\title{
ESTIMATIVAS DE EROSIVIDADE E AS PRECIPITAÇÕES DIÁRIAS EXTREMAS NA BACIA HIDROGRÁFICA DO RIO ALTO IGUAÇU - PARANÁ
}

\author{
TERASSI, Paulo Miguel de Bodas - pmbterassi@usp.br \\ Universidade de São Paulo / USP
}

BIFFI, Vitor Hugo Rosa - vhugorosabiffi@gmail.com

Universidade Estadual de Maringá / UEM

GALVANI, Emerson - egalvani@usp.br

Universidade de São Paulo / USP

OLIVEIRA-JÚNIOR, José Francisco - jose.junior@icat.ufal.br

Universidade Federal de Alagoas / UFAL

\begin{abstract}
RESUMO: Este artigo tem como objetivo estimar o potencial erosivo e avaliar a frequência e a intensidade das precipitações diárias na bacia hidrográfica do rio Alto Iguaçu, Paraná - Brasil. Utilizaram-se os dados diários, mensais e anuais de vinte e um postos pluviométricos para uma série de quarenta anos (1976-2015). As estimativas de erosividade foram calculadas a partir da equação apresentada por Rufino et al. (1993) para o estado do Paraná. A classificação dos totais diários de precipitação foi definida pela técnica de quantis. Utilizou-se a análise multivariada com base na técnica de análise de agrupamento (AA) segundo o método de Ward. Os resultados obtidos indicaram que as estações do verão e primavera concentram cerca de $70 \%$ do total pluvial anual. A técnica de AA identificou 4 grupos homogêneos (GH I, II, III e IV) e um posto pluviométrico anômalo (PPA). Os setores de maior erosividade, intensidade e frequência das precipitações diárias são o oeste e o PPA de Piraquara (Mananciais da Serra).
\end{abstract}

PALAVRAS-CHAVES: erosividade; chuvas intensas; variabilidade pluvial.

EROSIVITY ESTIMATES AND THE EXTREME DAILY RAINFALL IN THE ALTO IGUAÇU RIVER WATERSHED - PARANÁ

ABSTRACT: This paper aims to estimate erosion potential and to evaluate the frequency and intensity of daily rainfall in the Alto Iguaçu river watershed, Paraná - Brazil. Were used the daily, monthly and annual rainfall data of twenty one rain gauges in the forty years temporal serie (1976-2015). The rainfall erosivity estimates were calculated from the equation presented by Rufino et al. (1993) for the Paraná state. The classification of daily rainfall totals was defined by the quantiles technique. Was used the clustering analysis (AC) technique according to Ward's method. The results indicated that summer and spring concentrate about $70 \%$ of total rainfall annual. The AC technique identified 4 homogeneous groups (HG I, II, III e IV) and one anomalous pluviometric Station (PPA). The sectors with the highest erosivity, intensity and frequency of daily rainfall are the west and PPA in Piraquara (Mananciais da Serra).

KEYWORDS: erosivity; heavy rainfall; rainfall variability

\section{INTRODUÇÃO}

Um dos fatores componentes da Equação Universal de Perdas de Solos (EUPS), o fator $\mathrm{R}$ refere-se à erosividade, que corresponde a um dos agentes ativos da erosão (PRADO; NÓBREGA, 2005; SOUZA; GASPARETTO, 2012). O conhecimento da distribuição espacial e temporal do potencial erosivo permite identificar os setores e os períodos de maior susceptibilidade à ação deste fator, especialmente em bacias hidrográficas nas regiões tropical e subtropical (HOYOS et al., 2005; SILVA et al., 2011; MA et al., 2012). 
Segundo os estudos realizados por Panagos et al. (2017) para todo o Globo Terrestre, os climas tropicais apresentam valores de erosividade anuais médios de $7105 \mathrm{MJ} \cdot \mathrm{mm} \cdot \mathrm{ha}^{-1} \cdot \mathrm{h}^{-1} \cdot \mathrm{ano}^{-1}$, enquanto que as regiões áridas e frias apresentaram 843 e $494 \mathrm{MJ} \cdot \mathrm{mm} \cdot \mathrm{ha}^{-1} \cdot \mathrm{h}^{-1} \cdot \mathrm{ano}^{-1}$, respectivamente. Sendo assim, nos climas tropicais trata-se de um problema ambiental, principalmente em bacias hidrográficas em função da produção de sedimentos.

Para o território brasileiro, Silva (2004) elaborou o mapa de erosividade para o Brasil. Ele mostrou que $68,8 \%$ do país apresenta valores classificados entre forte e muito forte (>7357 MJ MJ.mm.ha ${ }^{-1} \cdot \mathrm{h}^{-1} \cdot \mathrm{ano}^{-1}$ ), com valores muito próximo aos verificados por Panagos et al. (2017). Os estudos realizados por Trindade et al. (2016) destacaram a elevada variabilidade espacial e temporal da erosividade no território brasileiro. Eles observaram que os maiores valores ocorrem entre novembro e fevereiro, período mais chuvosos para o Brasil Tropical, concordante com os resultados obtidos por Keller Filho et al. (2005).

No estado do Paraná, a mais recente estimativa de erosividade das chuvas foi realizada por Waltrick et al. (2015). Os autores identificaram o aumento generalizado do potencial erosivo pluvial nas regiões sudoeste, oeste, norte-pioneiro, centro-oriental e sudeste do estado em relação à equação proposta por Rufino et al. (1993). Estes estudos observaram que o Litoral e o sudoeste do Paraná correspondem aos setores de maior erosividade, sendo que o vale do Ribeira e a Região Metropolitana de Curitiba (RMC) apresentam os menores totais anuais de erosividade.

Nesta pesquisa, destaca-se a importância dos estudos das estimativas da erosividade das chuvas para a bacia hidrográfica do Alto Iguaçu (BHAI), pois se trata de uma região que possui características de uso e ocupação do solo muito peculiares; enquanto que a região mais próxima ao núcleo urbano de Curitiba se caracteriza pela densa urbanização e por problemas decorrentes de alagamentos e inundações, conforme discorre Zanella (2007), que são avarias ambientais que se relacionam diretamente com a força decorrente da energia cinética exercida pela erosividade; no entanto, nos setores adjacentes a RMC, verifica-se o domínio intensivo das atividades agropecuárias, setor no qual o planejamento depende restritamente do conhecimento das características pluviais e, em relação à erosividade, para o uso e manejo adequado do solo, de acordo com o que descrevem Tomazoni e Guimarães (2005).

Outro aspecto avaliado no presente trabalho são as precipitações diárias extremas, que é um indicador climático que possibilita inferir sobre a intensidade pluviométrica de certas localidades e regiões e sua ocorrência em determinados períodos, auxilia o planejamento e à gestão territorial para minimizar os impactos decorrentes dos eventos de grande magnitude, dentre os quais estão: a falta de água e alimentos, os movimentos de terra, os alagamentos e inundações, as mortes fatais, entre outros danos e malefícios (EASTERLING et al., 2000; SEPÚLVEDA; PETLEY, 2015; WU; HUANG, 2015).

Zanella et al. (2009), Amorim e Monteiro (2010), Oscar Júnior (2015) e Armond e Sant'Anna Neto (2019) destacam que as áreas urbanas dos ambientes tropicais são altamente susceptíveis aos impactos decorrentes dos eventos pluviais concentrados descritos acima dado as elevadas magnitudes inerentes a este tipo climático e, pujantemente, nas cidades brasileiras a urbanização acentuada e desordenada próprias às condições da desigualdade social predominante no Brasil e a ocupação desprovida de planejamento e 
ordenamento territorial são aspectos que e deflagram com maior frequência os episódios extremos, de acordo com a definição deste último conceito por Armond e Sant'Anna Neto (2017).

Deste modo, o estudo das precipitações extremas em bacias hidrográficas possibilita a compreensão da dinâmica hídrica e da susceptibilidade ambiental perante a esta condição climática. Sendo assim, o conhecimento da frequência e intensidade das precipitações extremas diárias na bacia hidrográfica do rio Alto Iguaçu (BHAI) é importante, visto que corresponde a um dos setores de maior densidade populacional do território paranaense, com mais de 3,27 milhões de habitantes, além de abrigar uma das maiores cidades brasileiras, Curitiba com mais de 1,9 milhões de habitantes (IBGE, 2018).

Igualmente relevante, o estudo das chuvas extremas diárias corresponde a um aspecto essencial para o planejamento das atividades agrícolas, uma vez que o conhecimento de seus padrões espaciais e temporais possibilitam planejar as etapas do calendário agrícola e implantar práticas de manejo que minimizem os impactos das chuvas de maiores totais concentrados. Sendo assim, as demais regiões da BHAI, que se caracterizam pela maior participação do setor primário, podem ter nesta pesquisa informações para minimizar nestas atividades a queda da produtividade relacionada aos impactos das elevadas alturas pluviométricas.

A técnica empregada nesta pesquisa para a classificação dos registros diários de precipitações foi a dos quantis, amplamente usada na classificação de atributos climáticos. Souza et al. (2012) aplicaram esta técnica com o objetivo de classificar a precipitação diária e verificar a relação destas com os desastres ambientais associados à ocorrência de chuvas extremas em Recife (PE). Gouvea et al. (2018) utilizaram a técnica dos quantis para a classificação da pluviosidade diária e anual na identificação de extremos pluviométricos na bacia hidrográfica do rio Itajaí, localizada em Santa Catarina, e destacaram a associação entre os anos mais chuvosos e a fase quente (El Niño) do modo de variabilidade El Niño-Oscilação Sul (ENOS). Terassi et al. (2018) avaliaram as classes de precipitação nas escalas anual, mensal e diária na região Norte do estado do Paraná a partir da técnica de quantis, que se mostrou eficiente para a identificação dos períodos mais secos e chuvosos e sua associação com o ENOS.

Portanto, a equação proposta por Rufino et al. (1993) e a técnica de quantis mostram-se eficazes para averiguar os períodos e os setores de maiores ou menores erosividade e dos totais pluviais diários, nesta ordem. Com base no exposto, este artigo objetiva estimar o potencial erosivo e avaliar a frequência e a intensidade das precipitações diárias na bacia hidrográfica do rio Alto Iguaçu, Paraná, Brasil.

\section{MATERIAIS E MÉTODOS}

\subsection{LOCALIZAÇÃO E CARACTERIZAÇÃo DA ÁREA DE ESTUDO}

A bacia hidrográfica do rio Alto do Iguaçu localiza-se no leste $(E)$ do estado do Paraná (PR), entre as coordenadas $25^{\circ} 15^{\prime} \mathrm{S}$ e $26^{\circ} 15^{\prime} \mathrm{S}$ e $48^{\circ} 5^{\prime} \mathrm{W}$ e $50^{\circ} 25^{\prime} \mathrm{W}$, conforme a delimitação do Instituto de Terras, Cartografia e Geodésia (ITCG, 2017). A área de estudo está inserida no Primeiro Planalto Paranaense, tendo como divisores naturais a Serra do Mar a leste e a Serra de São Luiz do 
Purunã a oeste (MAACK, 2012). A BHAI caracteriza-se pela predominância de rochas dos xistos metamórficos e gnaisses, cortados por diques de pegmatitos e intrusões graníticas (MINEROPAR, 2001) e altitudes médias entre 850 a 950 metros, conforme indica a Figura 1.

O clima predominante é o tipo "Cfb", conforme o método de classificação de Köppen (1948), segundo trabalhos realizados para o território nacional (ÁLVARES et al., 2013) e para o estado do Paraná (APARECIDO et al., 2016). Esta classificação climática indica um clima subtropical mesotérmico sem estação seca definida e temperatura do mês mais quente inferior a $22^{\circ} \mathrm{C}$ e do mês mais frio inferior a $18^{\circ} \mathrm{C}$. Terassi e Galvani (2017a) observaram que a área em estudo se caracteriza por totais anuais de precipitação entre $1464 \mathrm{~mm}$ e $1852 \mathrm{~mm}$.

Uma das principais características do clima Subtropical predominante na área de estudo dá se pela boa distribuição da pluviosidade ao longo do ano, com a atuação constante da frente polar atlântica, dos Complexos Convectivos de Mesoescala (CCM's) e ciclones decorrentes da atuação de vórtices ciclônicos e cavados em altos níveis sobre a costa oeste da América do Sul vindo do Pacífico (GRIMM, 2009, REBOITA et al., 2010). Com a principal estação meteorológica convencional da área em estudo, nota-se em Curitiba a maiores alturas médias de pluviosidade entre o trimestre de dezembro e fevereiro (>150 mm), sendo que somente em abril e agosto a média pluvial é inferior a $100 \mathrm{~mm}$. A temperatura média na capital paranaense é superior a $20^{\circ} \mathrm{C}$ somente em janeiro e fevereiro, com uma diminuição expressiva entre junho e agosto $\left(\left\langle 14^{\circ} \mathrm{C}\right)\right.$, condizente com a sazonalidade térmica regional (INMET, 2018) e concordante com as observações de Nimer (1989) e Reboita et al. (2012) sobre as características do clima Subtropical da região Sul brasileira.

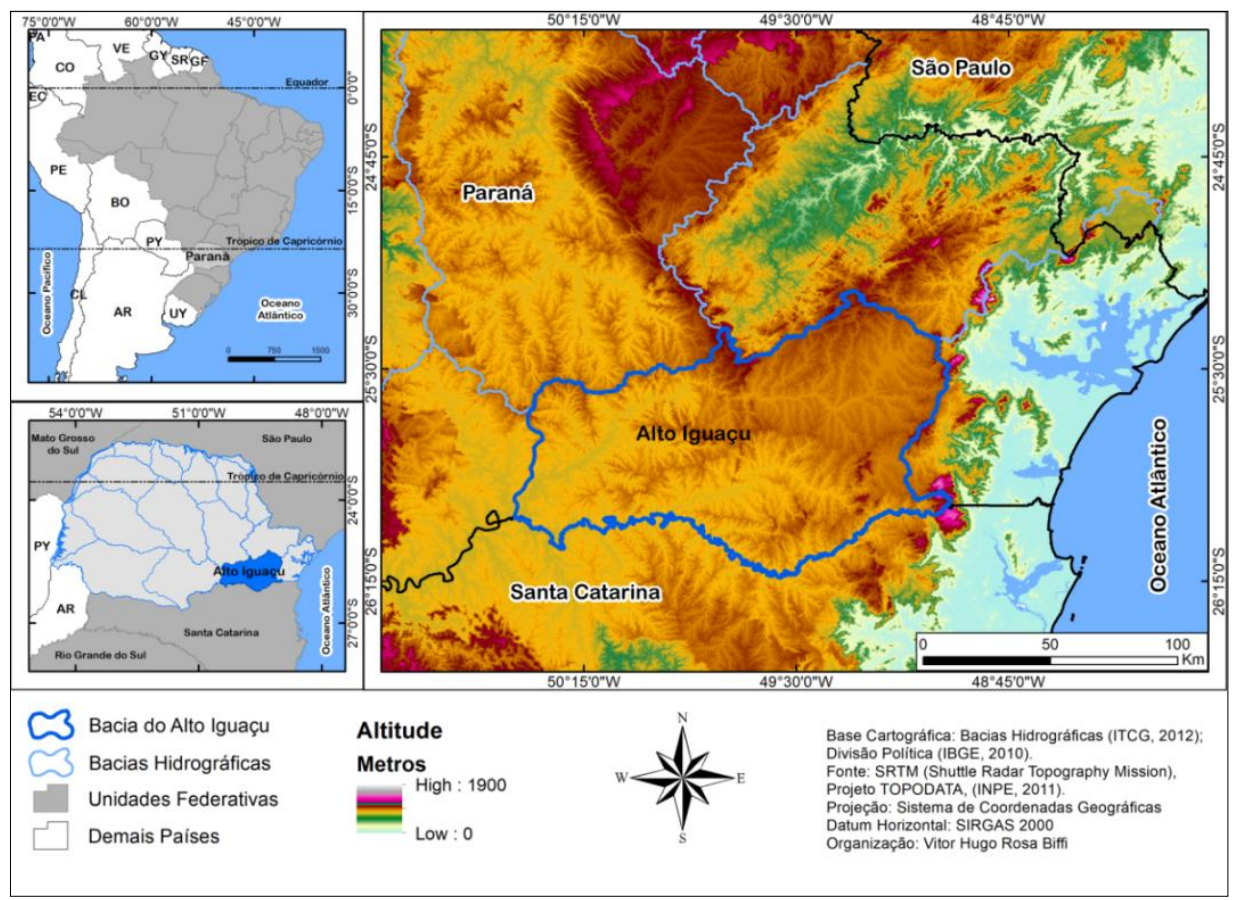

Figura 1 - Localização da área de estudo. 
Devido à regularidade das chuvas, à redução das médias térmicas e pelas ocorrências de geadas invernais, a Floresta Ombrófila Mista, tendo sua principal vegetação a Araucária Angustifolia, ocupa grande parte da BHAI (RODERJAN et al., 2002). Contudo, alguns setores apresentam vegetação original os relictos do clima semiárido do período Pleistoceno, os Campos naturais da estepe gramíneo-lenhosa (Campos Gerais), conforme descrevem Ritter et al. (2007).

Atualmente, os municípios mais populosos da BHAI concentram-se na RMC, sendo que a capital do estado do Paraná apresenta uma população estimada de 1.917.185 habitantes e corresponde ao oitavo município com o maior total de habitantes (IBGE, 2018). De modo geral, a maior densidade urbana e o predomínio de atividades econômicas industriais e de serviços concentram-se no setor nordeste da BHAI, no entorno da RMC e, por sua vez, o setor agrícola é predominante nas localidades mais distantes do núcleo urbano de Curitiba (IPARDES, 2016).

\subsection{PROCEDIMENTOS METODOLÓGICOS}

Foram utilizados os dados pluviométricos mensais e anuais de 21 postos pluviométricos junto a Agência Nacional de Águas (ANA) e Companhia Paranaense de Energia (COPEL), Instituto Agronômico do Paraná (IAPAR), Instituto Águas do Paraná, Instituto Nacional de Meteorologia (INMET) e Sistema Meteorológico do Paraná (SIMEPAR), para o período de 1976 a 2015 (Quadro 1).

O principal critério de seleção dos postos pluviométricos foram as falhas de registros menores que $5 \%$, sendo que os dados faltantes foram preenchidos pelo método de ponderação regional (VILLELA; MATOS, 1975).

Quadro 1 - Informações dos postos pluviométricos situados na BHAI - Paraná.

\begin{tabular}{|c|c|c|c|c|c|}
\hline No & $\begin{array}{c}\text { Postos } \\
\text { Pluviométricos }\end{array}$ & $\begin{array}{c}\text { Alt. } \\
(\mathbf{m})\end{array}$ & $\begin{array}{c}\text { Lat. } \\
\mathbf{( o S )}\end{array}$ & $\begin{array}{c}\text { Long. } \\
(\mathbf{o W})\end{array}$ & Entidades \\
\hline 1 & Campo Largo & 901 & 25,47 & 49,57 & Águas do Paraná \\
\hline 2 & Curitiba & 923 & 25,43 & 49,26 & INMET \\
\hline 3 & Lapa & 903 & 25,80 & 49,88 & Águas do Paraná \\
\hline 4 & Lapa & 929 & 25,70 & 50,01 & Águas do Paraná \\
\hline 5 & Lapa & 750 & 25,93 & 49,78 & Águas do Paraná \\
\hline 6 & Mandirituba & 920 & 25,78 & 49,32 & Águas do Paraná \\
\hline 7 & Pinhais & 930 & 25,42 & 49,13 & IAPAR/SIMEPAR \\
\hline 8 & Piraquara & 979 & 25,49 & 48,99 & Águas do Paraná \\
\hline 9 & Piraquara & 900 & 25,45 & 49,07 & ANA \\
\hline 10 & Porto Amazonas & 793 & 25,55 & 49,88 & COPEL \\
\hline 11 & São José dos Pinhais & 910 & 25,52 & 49,15 & Águas do Paraná \\
\hline 12 & São Mateus do Sul & 770 & 26,09 & 50,33 & COPEL \\
\hline 13 & São Mateus do Sul & 760 & 25,55 & 50,39 & COPEL \\
\hline 14 & São Mateus do Sul & 770 & 25,95 & 50,57 & COPEL \\
\hline 15 & São João do Triunfo & 856 & 25,62 & 50,20 & Águas do Paraná \\
\hline 16 & Rio Negro & 770 & 26,10 & 49,80 & COPEL \\
\hline 17 & Tijucas do Sul & 913 & 25,82 & 49,15 & Águas do Paraná \\
\hline 18 & Piên & 790 & 26,15 & 49,38 & COPEL \\
\hline 19 & Quitandinha & 820 & 25,87 & 49,50 & ANA \\
\hline 20 & Quitandinha & 810 & 25,95 & 49,38 & ANA \\
\hline
\end{tabular}




\begin{tabular}{|l|l|l|l|l|l|}
\hline 21 & Palmeira & 951 & 25,50 & 50,08 & Águas do Paraná \\
\hline
\end{tabular}

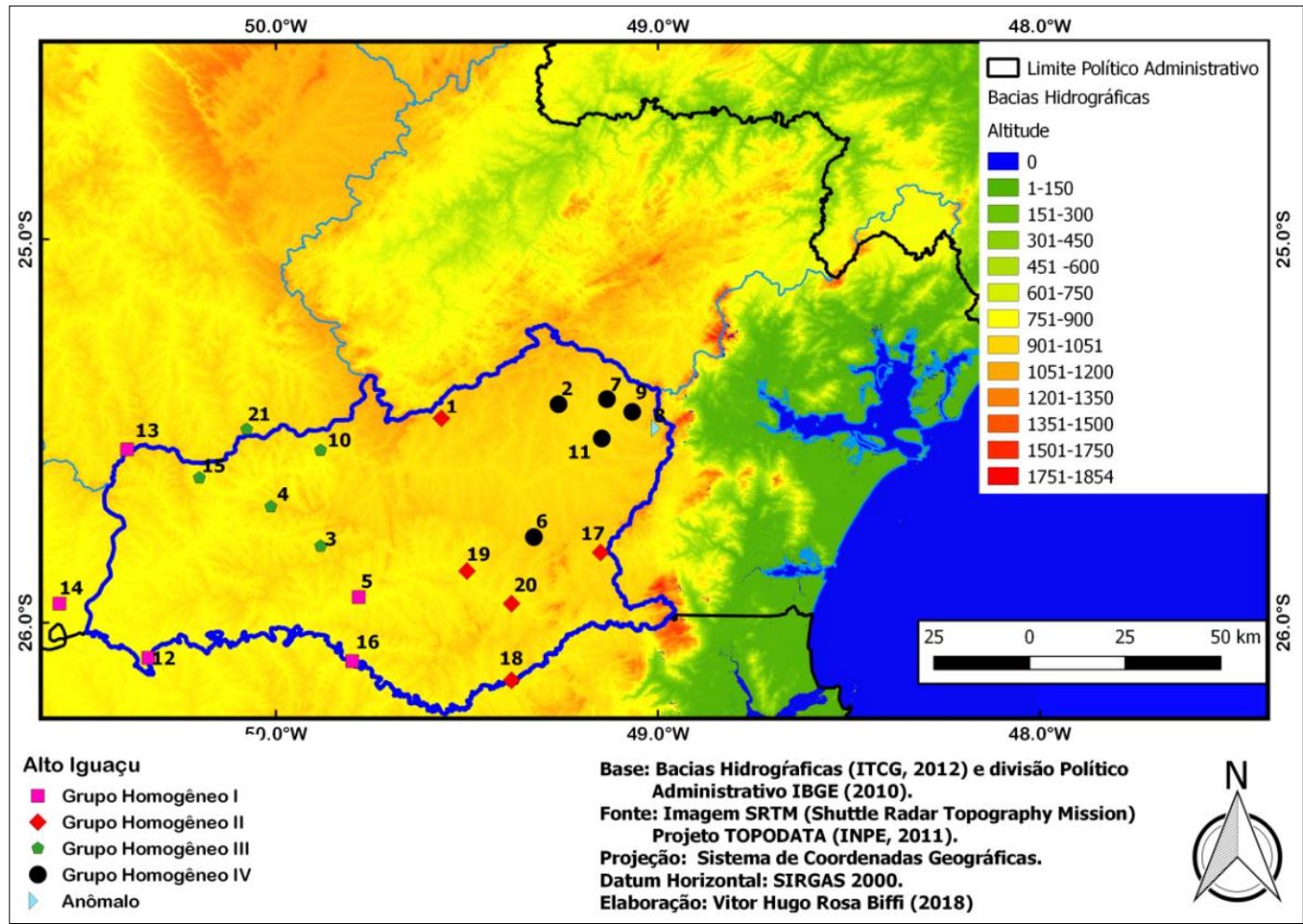

Figura 2 - Localização dos grupos homogêneos (GH I, II, III e IV) da BHAI - Paraná e altitude $(m)$, respectivamente.

Os gráficos de pluviosidade e erosividade foram elaborados a partir da utilização do Microsoft Office Excel 2007 e o software Statistica 7.0, sendo este último também utilizado para a análise de agrupamento (AA). Este procedimento (clustering) adaptado neste trabalho foi previamente publicado por Terassi e Galvani (2017a) e aplicado com a finalidade definir as regiões homogêneas quanto à distribuição espaço-temporal da pluviosidade (Figura 2).

Para a realização da técnica de $A A$, utilizou-se como medida de proximidade a distância Euclidiana ao quadrado, que segundo Freitas et al. (2013), é comumente a mais utilizada para a análise de variáveis quantitativas. Aplicou-se o método de Ward (1963), considerado o mais apropriado para a análise de agrupamento, uma vez que este método propõe que em qualquer fase de análise a perda de informação que resulta do agrupamento de elementos seja medida pela soma dos quadrados dos desvios de cada elemento à média dos elementos do grupo à qual pertence (NASCIMENTO et al., 2015).

O índice de erosividade foi calculado com base na utilização dos dados médios mensais e anuais dos 21 postos pluviométricos. Para estabelecer os valores do índice erosividade (EIm) foi utilizada a equação do tipo $Y=a+b x$, em que: $Y=$ índice de erosão (MJ.mm.ha $\left.{ }^{-1} \cdot \mathrm{h}^{-1} \cdot \mathrm{ano}^{-1}\right) ; \mathrm{a}$ e $\mathrm{b}=$ coeficientes linear e angular, e $\mathrm{x}=\mathrm{p} 2 / \mathrm{P}$ (pluviosidade mensal ao quadrado dividida pela pluviosidade anual), apresentada por Rufino, Biscaia e Merten (1993) para o 
estado do Paraná. Os valores determinados para a área de estudo encontram-se predominantemente na região isoerosiva $8(Y=3,39+4,15 x)$. Essas atribuições deram parâmetro para a equação 1 .

$$
E I_{m}=3,39+4,15\left(\frac{p^{2}}{P}\right)^{9,80665}
$$

Em que: EIm - Índice mensal de erosividade em MJ $\left(\mathrm{mm} \cdot \mathrm{ha}^{-1} \cdot \mathrm{h}^{-1} \cdot \mathrm{mês}^{-1}\right) ; \mathrm{a}$ coeficiente linear $(3,39)$; b - coeficiente angular $(4,15) ; p$ - Precipitação média mensal em milímetros; P - Precipitação média anual em milímetros; 9,80665 Conversão kgf (quilograma força) para MJ (Megajoule).

Determinou-se que um dia chuvoso corresponde ao registro igual ou superior a $1 \mathrm{~mm}$, conforme as normas do INMET (INMET, 2018). Definiu-se como critério a precipitação diária acumulada em 24 horas com a utilização da técnica dos quantis, que se baseia na distribuição da frequência acumulada, sendo que a aproximação da função densidade de probabilidade (FDP).

Os intervalos de cada percentil representam as probabilidades ou frequências esperadas para cada um dos eventos que podem ocorrer na sequência da série temporal de uma variável x (ANANIAS et al., 2010; SANTOS et al., 2016). Para estabelecer as classes em relação aos valores observados $\left(x_{i}\right)$ de chuva foram utilizadas as ordens quantílicas, em que $Q$ significa o limite do quantis, conforme adotado por Souza et al. (2012), para a classificação dos registros pluviais ( $<25 \%, \geq 50 \%, \geq 75 \%, \geq 95 \%$ e $\geq 99 \%$ ).

\section{RESULTADOS E DISCUSSÕES}

\subsection{CARACTERIZAÇÃO PLUVIAL E O POTENCIAL EROSIVO}

A BHAI caracteriza-se pelo total médio anual de $1571,4 \mathrm{~mm}$. Os grupos homogêneos (GH) I e II correspondem aos setores de maiores totais anuais de precipitação, $1611,4 \mathrm{~mm}$ e $1592,7 \mathrm{~mm}$, nesta ordem, e em postos pluviométricos situados no noroeste, oeste e sul da BHAI. Entretanto, a maior pluviosidade média anual foi observada no posto pluviométrico anômalo (PPA) em Piraquara (Mananciais da Serra), igual a 1852,5 mm, devido à influência da orografia, uma vez que se situa a uma altitude de $979 \mathrm{~m}$ (Quadro 1), a mais elevada dentre os pontos de registros selecionados para pesquisa (Figura 3).

O GH IV corresponde ao setor de menores totais anuais de pluviosidade da BHAI $(1463,6 \mathrm{~mm})$, o que se atribui a localização a sotavento da Serra do Mar. Em uma condição intermediária aos demais setores, o GH III apresenta uma média anual de pluviosidade próximo à média de toda bacia hidrográfica $(1561,2 \mathrm{~mm})$ e situa-se majoritariamente no setor SE da área em estudo (Figura 3).

Quanto à distribuição temporal, verifica-se que os maiores totais anuais da BHAI estão associados em sua maioria aos eventos mais intensos do modo de variabilidade climática ENOS e suas respectivas fases (EI Niño e La Niña). Os anos de 1983, 1998, 2010 e 2015 mostraram uma média anual superior a 1900 $\mathrm{mm}$ para a média da BHAI e estiveram sob domínio parcial ou total da fase quente do ENOS (El Niño), que segundo Grimm et al. (2000), Nery e Carfan 
(2014) e Tedeschi et al. (2015), é o período de maior aumento da pluviosidade em função da atuação da fase quente do ENOS.

Por sua vez, a fase fria do ENOS (La Niña) mostrou-se preponderante ao determinar os menores totais anuais da ordem de $1200 \mathrm{~mm}$ nos anos de $1978 \mathrm{e}$ 1985, sendo corroborado pelos resultados obtidos por Baldo et al. (2001) e Nery et al. (2005), de que a La Niña atua com menor intensidade e frequência para a redução da pluviometria no estado Paraná em relação ao El Niño. Entretanto, destaca-se que não necessariamente um determinado período com a atuação do El Niño registrará totais anuais mais elevados, como houve em 2006 (1142,2 $\mathrm{mm})$, e também em condições de La Niña não será observado impreterivelmente os menores totais de pluviosidade, como observado em 2011 $(1804,9 \mathrm{~mm})$, conforme demonstra a figura 3 .

A BHAI obteve uma erosividade média anual de $7128,7 \mathrm{MJ} . \mathrm{mm} \cdot \mathrm{ha}^{-1} \cdot \mathrm{h}^{-}$ ${ }^{1}$. ano ${ }^{-1}$. Os maiores valores foram observados no PPA e no GH I, equivalentes a 8108,6 e 7423,1 MJ.mm.ha ${ }^{-1} \cdot \mathrm{h}^{-1}$.ano ${ }^{-1}$, e, inversamente, os setores de menor erosividade correspondem ao GH II e IV, situados ao norte e nordeste da BHAI, com 7056,2 e 6717,4 MJ.mm.ha ${ }^{-1} \cdot \mathrm{h}^{-1}$.ano ${ }^{-1}$. Por sua vez, o GHIII mostrou uma erosividade média anual de 7122,1 MJ.mm.ha ${ }^{-1} \cdot \mathrm{h}^{-1} \cdot \mathrm{ano}^{-1}$ (Figura 4). Estes resultados para a BHAI estão alinhados aos resultados anteriores obtidos por Silva (2004), Oliveira et al. (2012) e Trindade et al. (2016) para este setor do território brasileiro e por Waltrick et al. (2015) neste setor paranaense, que estiveram entre 6000 e $8000 \mathrm{MJ} \cdot \mathrm{mm} \cdot \mathrm{ha}^{-1} \cdot \mathrm{h}^{-1} \cdot \mathrm{ano}^{-1}$.

Os anos de 1978 e 1985, ambos em condições de La Niña, 1981 e 2003, sob neutralidade, e 2006, com a atuação do El Niño, obtiveram erosividade inferior a $6000 \mathrm{MJ} . \mathrm{mm} \cdot \mathrm{ha}^{-1} \cdot \mathrm{h}^{-1}$. ano ${ }^{-1}$ para a média da BHAI. Os anos de 1983, 1998 e 2009, sob condições de EN, e 2010, com a atuação alternada de EN e $\mathrm{LN}$, obtiveram erosividade superior $8500 \mathrm{MJ} \cdot \mathrm{mm} \cdot \mathrm{ha}^{-1} \cdot \mathrm{h}^{-1} \cdot \mathrm{ano}^{-1}$ (Figura 4). Portanto, nota-se a atuação predominante das fases do ENOS para a ocorrência dos maiores e menores valores de erosividade na área de estudo, especialmente para o El Niño e o aumento do potencial erosivo, concordante com o observado por Waltrick et al. (2011) para o Paraná.

Terassi e Galvani (2017b) avaliaram o potencial erosivo nas bacias hidrográficas do Ribeira e Litorânea, no leste do estado do Paraná, e indicaram que alguns setores do litoral apresentam erosividade média anual superior a $12.000 \mathrm{MJ} \cdot \mathrm{mm} \cdot \mathrm{ha}^{-1} \cdot \mathrm{h}^{-1}$. ano ${ }^{-1}$. Por outro lado, os setores de menores elevações do vale do Ribeira caracterizam-se por valores inferiores a $6.000 \mathrm{MJ} . \mathrm{mm} \cdot \mathrm{ha}^{-1} \cdot \mathrm{h}^{-}$ ${ }^{1}$. ano ${ }^{-1}$, o que se deve ao controle da proximidade do Oceano Atlântico e a orografia da Serra do Mar na distribuição espacial da pluviosidade nestas bacias hidrográficas. Para a BHAI, observa-se menor variação das altitudes entre os postos pluviométricos utilizados, entre 750 a $930 \mathrm{~m}$, responde pela menor variação espacial da erosividade, o que é concordante ao observado por Cândido e Nunes (2008) e Brito et al. (2016) sobre a importância e influência do relevo na espacialidade da precipitação pluviométrica.

Netto et al. (2018) mostraram para Pinhais, localizada no GH IV, um dos menores totais anuais de erosividade para o estado do PR $\left(5675,1 \mathrm{MJ} . \mathrm{mm}^{-\mathrm{ha}^{-}}\right.$ ${ }^{1} \cdot \mathrm{h}^{-1}$.ano ${ }^{-1}$ ), o que se atribui a sua localização à sotavento da Serra do Mar, condição observada anteriormente por Waltrick et al. (2015) para este setor paranaense. 


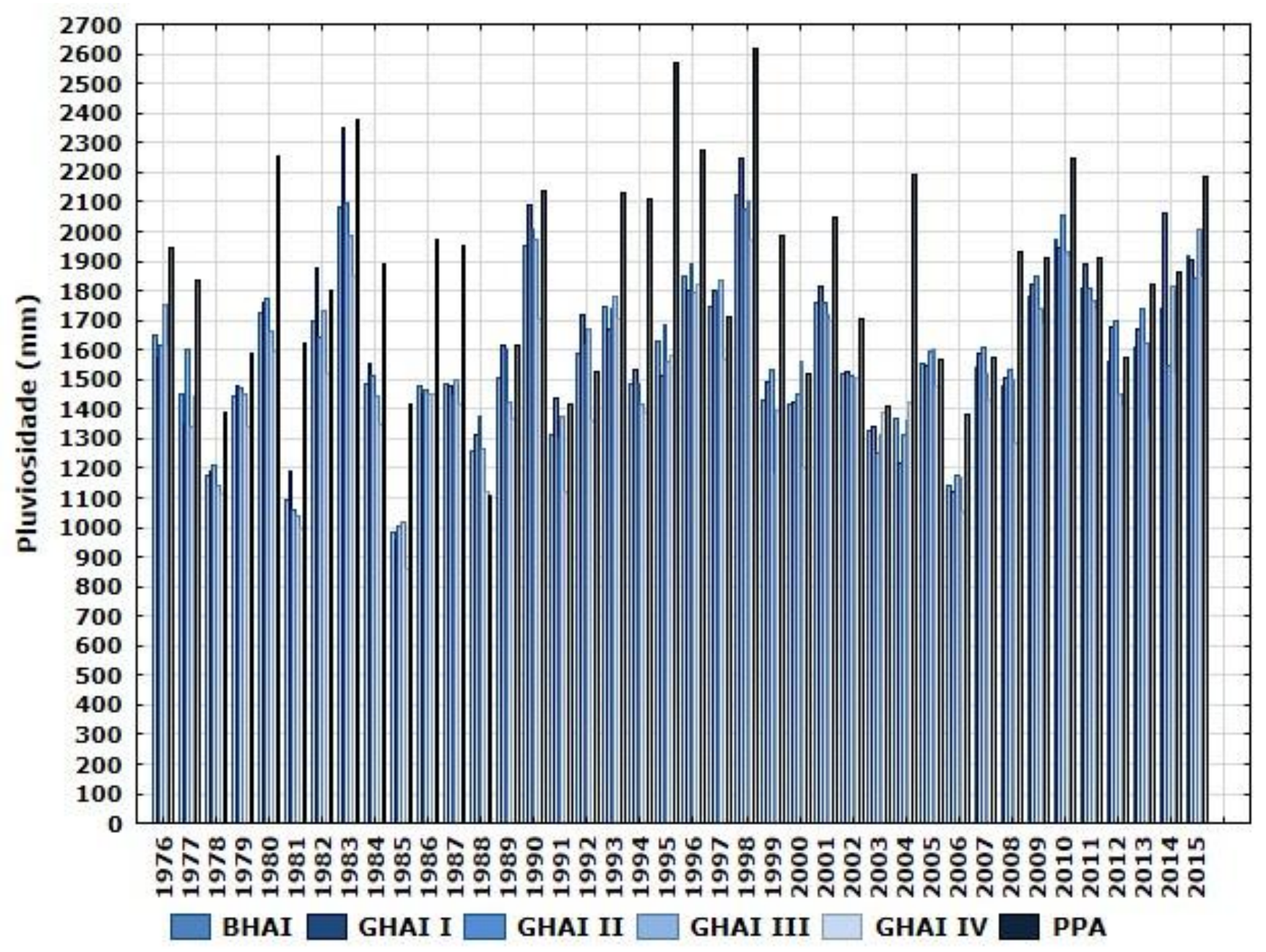

Figura 3 - Pluviosidade média anual (mm) dos grupos homogêneos (GH) para a bacia hidrográfica do rio Alto Iguaçu - PR. 


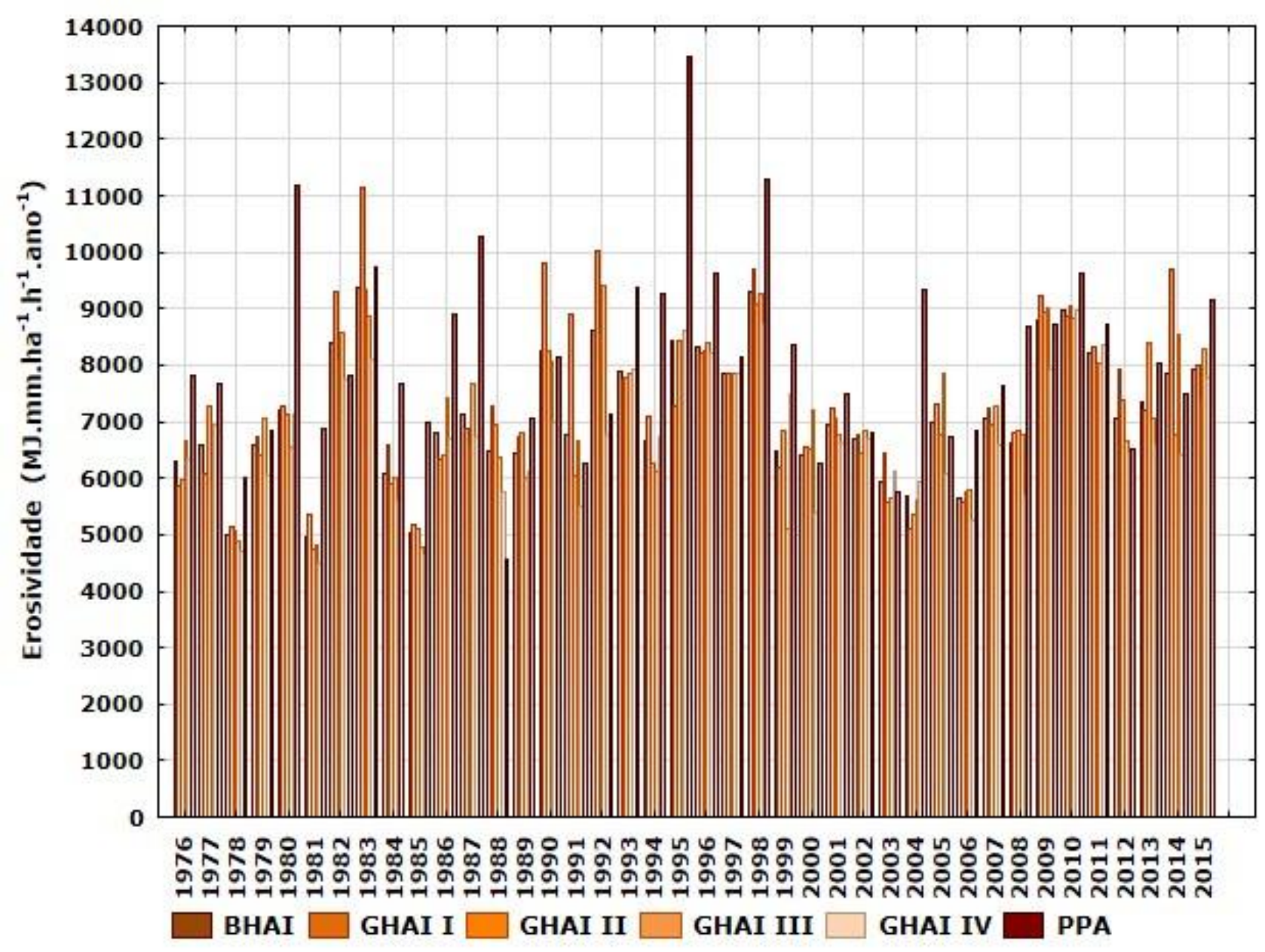

Figura 4 - Estimativas de erosividade média anual (MJ.mm.ha- ${ }^{-1} \cdot \mathrm{h}^{-1} \cdot \mathrm{ano}^{-1}$ ) dos grupos homogêneos (GH) para a bacia hidrográfica do rio Alto Iguaçu - PR. 
Sobretudo, a principal diferença entre os setores de maior ou menor erosividade está na distribuição mensal pluviométrica, posto que os setores do estado do PR com o maior erosividade são aqueles em que apresentam as maiores alturas de pluviométricas, como por exemplo, os meses de maio e outubro para os setores oeste e sudoeste (WALTRICK et al., 2015) ou as médias mensais maiores que $300 \mathrm{~mm}$ no trimestre de janeiro a março no litoral (TERASSI; GALVANI, 2017b), na qual a erosividade anual supera os 10000 MJ.mm.ha- ${ }^{-1} \cdot \mathrm{h}^{-1} \cdot \mathrm{ano}^{-1}$. No entanto, as regiões com uma distribuição mensal mais homogênea da pluviosidade são aquelas que apresentam os menores valores anuais e mensais de erosividade.

Os maiores totais de pluviosidade na BHAI se dão em janeiro, fevereiro, outubro e dezembro, com média superior a $150 \mathrm{~mm}$, e os menores totais são observados em abril e agosto, 94 e 84 mm (Figura 5). Desta forma, observa-se que existe uma tendência de maior pluviometria entre setembro e março, que se configura com uma característica própria ao clima tropical, no qual a atuação conjugada destes diferentes mecanismos intertropicais responde pelo aumento da pluviosidade: a Zona de Convergência do Atlântico Sul (ZCAS), a Zona de Convergência de Umidade (ZCOU), as Linhas de Instabilidades (LI) e os CCM's (SELUCHI; CHOU, 2009; QUADRO et al., 2012; MELLO et al., 2017).

Entretanto, como se trata uma região de clima subtropical (ÁLVARES et al., 2013; APARECIDO et al., 2016), as características pluviométricas da região mantém uma menor diminuição da pluviosidade nos meses de outono e inverno em relação ao clima tropical, conforme observaram Fritzsons et al. (2011) e Wrege et al. (2016) para o estado do PR. Isto se dá devido à atuação frequente e significativa da frente polar atlântica (FPA) na geração de precipitação no Sul do Brasil durante o inverno (REBOITA et al., 2010; CARDOZO et al., 2015), com a menor participação dos mecanismos intertropicais na dinâmica atmosférica.

O PPA mostrou maiores volumes totais de pluviosidade em quase todos os meses, com exceção de agosto e junho. Dentre os grupos homogêneos, notase que o GH II apresenta as maiores médias entre dezembro e março e que o GH I mostra os maiores valores de precipitação entre abril e novembro. O GH IV é a área de maior redução da pluviosidade nos meses menos chuvosos, em abril (85 mm) e agosto $(74 \mathrm{~mm})$, segundo a figura $5 \mathrm{a}$. Observa-se que as maiores diferença de pluviosidade entre os GH ocorrem nos meses mais chuvosos, entre setembro e março, período de maior probabilidade de ocorrência das precipitações convectivas, ao passo que durante os demais meses a pluviosidade é espacial mais homogênea, posto que o principal mecanismo de geração da precipitação é a FPA (BORSATO; MENDONÇA, 2015). Inclusive, este padrão de variação espacial entre os meses mais secos e chuvosos foram observados por Terassi e Galvani (2017b) para as BH's do Ribeira e Litorânea (PR). 


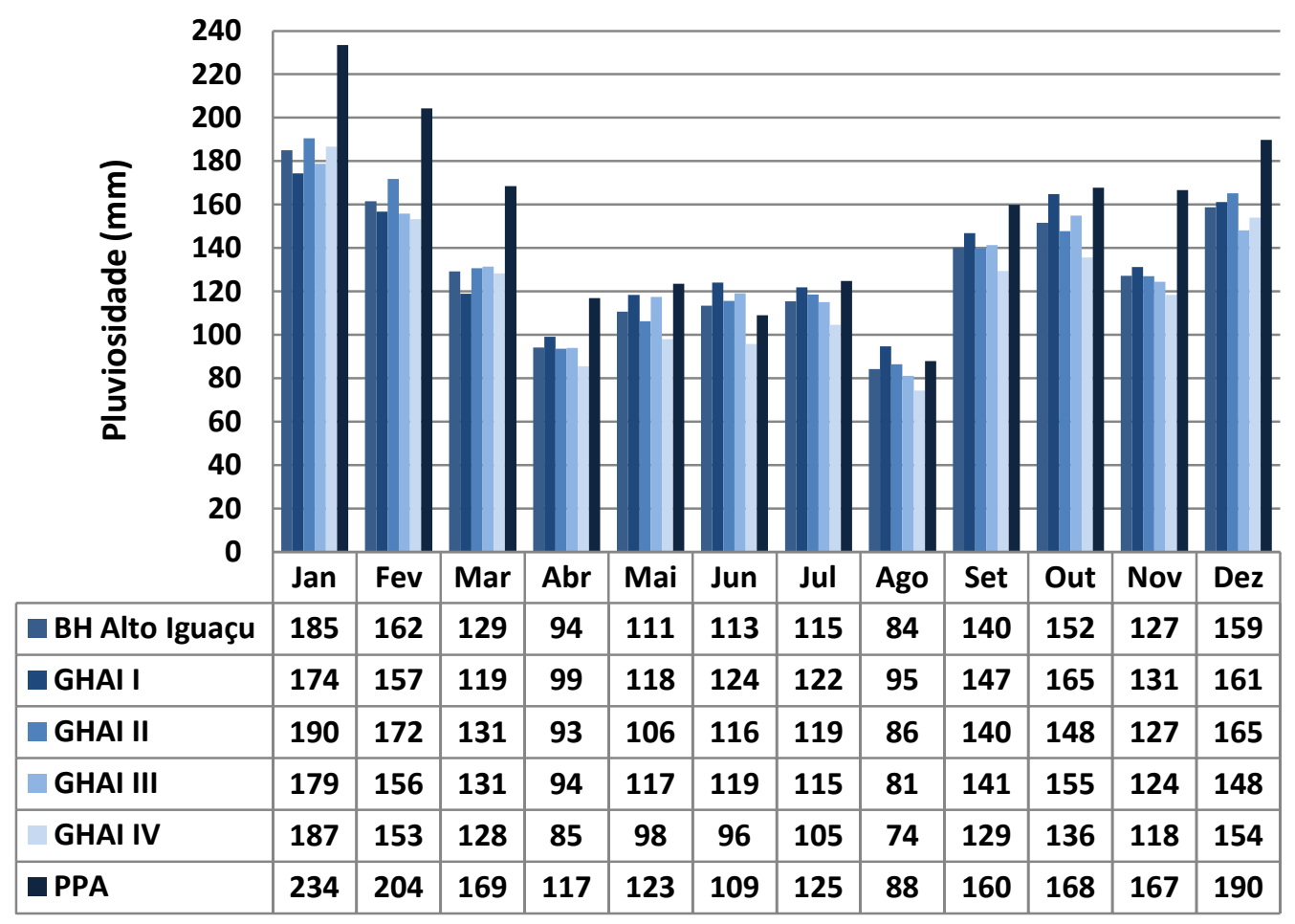

Figura 5 - Pluviosidade média mensal $(\mathrm{mm})$ dos grupos homogêneos $(\mathrm{GH})$ para a bacia hidrográfica do Alto Iguaçu - PR.

O mês de janeiro é isoladamente o de maior potencial erosivo para toda a BHAI, com destaque para as médias observadas no GH IV e PPA, equivalentes a 1152 e $1329 \mathrm{MJ}$. mm.ha ${ }^{-1} \cdot \mathrm{h}^{-1} \cdot \mathrm{mês}^{-1}$. O mês de menor erosividade é agosto, com média inferior a $300 \mathrm{MJ}$. mm.ha-1 $\cdot \mathrm{h}^{-1} \cdot \mathrm{mês}^{-1}$, exceção dada pelo GHI, setor da BHAI que apresenta a menor redução da pluviosidade no mês menos chuvoso. O período de setembro a março corresponde ao período de maior atenção à erosividade, pois concentra 70,6\% deste parâmetro na BHAI (Figura 6), resultado semelhante ao observado por Tommaselli et al. (1999) para o oeste paulista e Schick et al. (2014) para o oeste catarinense, e inferior aos 94\% observados por Almeida et al. (2012) no estado do Mato Grosso, no qual o clima tropical caracteriza-se por uma maior concentração sazonal pluviométrica.

Observa-se que os GH I e GH III mostram de forma mais significativa dois repiques significativos de erosividade em maio e outubro (Figura 6b), o que é concordante ao observado por Silva (2004) para o oeste da região Sul do Brasil, por Waltrick et al. (2015) para o oeste e sudoeste paranaense e por Back e Poleto (2018) para o oeste do estado de Santa Catarina. Segundo Waltrick et al. (2015), as associações dos jatos de baixo nível aos jatos subtropicais formam os CCM's, sistemas atmosféricos que junto às FP aumentam os totais pluviométricos e o potencial da erosivo nos meses de maio e outubro. 


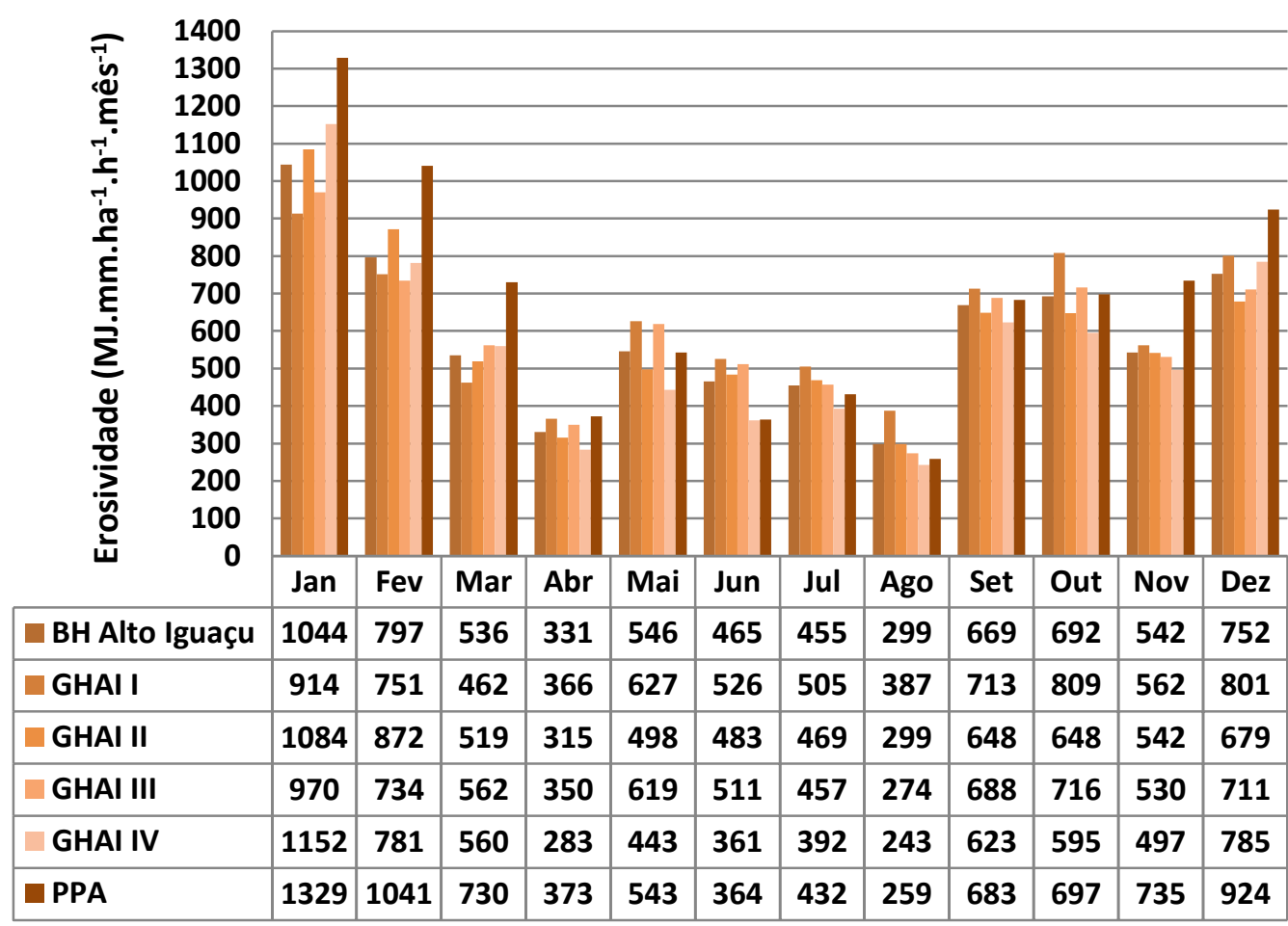

Figura 6 - Estimativas de erosividade média mensal (MJ. mm.ha ${ }^{-1} \cdot \mathrm{h}^{-1} \cdot \mathrm{mês}^{-1}$ ) dos grupos homogêneos $(\mathrm{GH})$ para a bacia hidrográfica do Alto Iguaçu - PR.

\subsection{INTENSIDADE E FREQUÊNCIA DAS PRECIPITAÇÕES DIÁRIAS}

A estatística descritiva e exploratória aplicada à série temporal das precipitações diárias possibilitou indicar a intensidade deste atributo climático nos GH da BHAI. Os maiores extremos de precipitações diárias, indicados pelo quantis de $99 \%$ (78,0 mm) e 99,9\% (139,9 mm) foram obtidos no PPA, sendo, desta forma, o setor da área de estudo com os registros diários mais intensos. No entanto, para os quantis de $50 \%$ (mediana) e $95 \%$, os valores mais elevados foram observados no $\mathrm{GH}$ I, iguais a $10,2 \mathrm{~mm}$ e $47,0 \mathrm{~mm}$, nesta ordem. Sobretudo, os valores dos intervalos e o máximo de precipitações diárias foram substancialmente maiores no GH I em relação ao PPA, embora os resultados dos quantis tenha mostrado que a distribuição do conjunto de dados diários seja maior no PPA (Figura 7).

Em relação aos grupos homogêneos, o GH I mostrou os maiores valores em todas as classes delimitadas de precipitações diárias, seguido do GH III, tendo esse último os maiores resultados dos quantis em relação ao GH II e ao GH IV. O setor com os menores totais anuais de pluviosidade e erosividade da BHAI, o GH IV também é aquele de menor intensidade das precipitações diárias (Figura 8). Portanto, é possível estabelecer que o maior potencial erosivo não ocorra necessariamente proporcional ao total anual pluviométrico, mas devido à distribuição mensal e diária das precipitações, uma vez que o GH II, mesmo com maiores alturas médias anuais em relação ao GH III, apresentou menor erosividade média anual e precipitações diárias menos intensas. Tais resultados se assemelham aos observados por Terassi et al. (2016) na relação entre 
precipitação diária e erosividade para a Unidade Hidrográfica dos rios Pirapó, Paranapanema III e IV, no norte paranaense.

Os resultados se assemelham aos obtidos por Zandonadi (2015) para Curitiba (PR), que observaram $60 \mathrm{~mm}$ para a classe de $98 \%$ dos quantis, totais de precipitações considerados por Zanella (2006) como o limiar delimitativo para a ocorrência dos maiores impactos em ambientes urbanos. Analisando comparativamente, Souza et al. (2012) obteve 55,3 $\mathrm{mm}$ para $95 \%$ dos quantis para Recife (PE), situada no litoral nordestino. Wanderley et al. (2018) notaram que Recife apresenta precipitações elevadas ( $>100 \mathrm{~mm}$ ) somente entre março e julho, período mais chuvoso e que apresenta mais riscos e probabilidade de retorno das precipitações extremas.

O mês de janeiro é isoladamente o mês com maior frequência de dias chuvosos para a área de estudo. O período de setembro a março concentra em média cerca de $70 \%$ do número de dias chuvosos na BHAI. Destaca-se que os postos pluviométricos representativos do GH II e IV apresentam similaridades na distribuição dos meses com maior registro de precipitações superiores a 99\% dos quantis, que são mais frequentes em junho, enquanto que nos GH I e no PPA o mês com maior registro de precipitações acima de tal limiar é identificada no mês de maio. Para o GH III, as precipitações acima de $99 \%$ dos quantis são mais frequentes em fevereiro (Figuras 9 e 10).

As precipitações entre $95 \%$ e $99 \%$ dos quantis são superiores a 15 dias para a série histórica em análise para todos os postos pluviométricos analisados em janeiro e dezembro, meses da estação do verão, e em setembro, no mês que dá início a primavera e há a regularização das precipitações. Para o PPA e os postos pluviométricos dos GH III e IV verifica-se que os meses de fevereiro e março registraram um número superior a 15 dias com precipitações entre o intervalo citado acima. Em outubro há um aumento significativo dos totais pluviais e da erosividade nos postos pluviométricos do GH I e III, que pode estar relacionado com o aumento de precipitações entre R95p e R99p. Sobre tal indicador, observa-se que em Quitandinha (GH II) e São Mateus do Sul (GH I) verifica-se um número superior a 15 dias de registros no mês de junho, atrelando-se a maior influência da FP na geração das precipitações mais frequentes nestas áreas (Figuras 9 e 10).

Para a região Norte do Estado do Paraná (RPN), Terassi et al. (2018) indicaram valores entre $46,0 \mathrm{~mm}$ a $49,8 \mathrm{~mm}$ para os quantis de $95 \%$ e entre $73,0 \mathrm{~mm}$ e $78,2 \mathrm{~mm}$ para os quantis de $99 \%$. Mostraram também que a RPN se caracteriza pela concentração das precipitações diárias para os intervalos de $25 \%, 50 \%$ e $75 \%$ são mais evidentes em julho e agosto, além do aumento das precipitações diárias superiores a $95 \%$ e a $99 \%$ dos quantis entre setembro e março. 


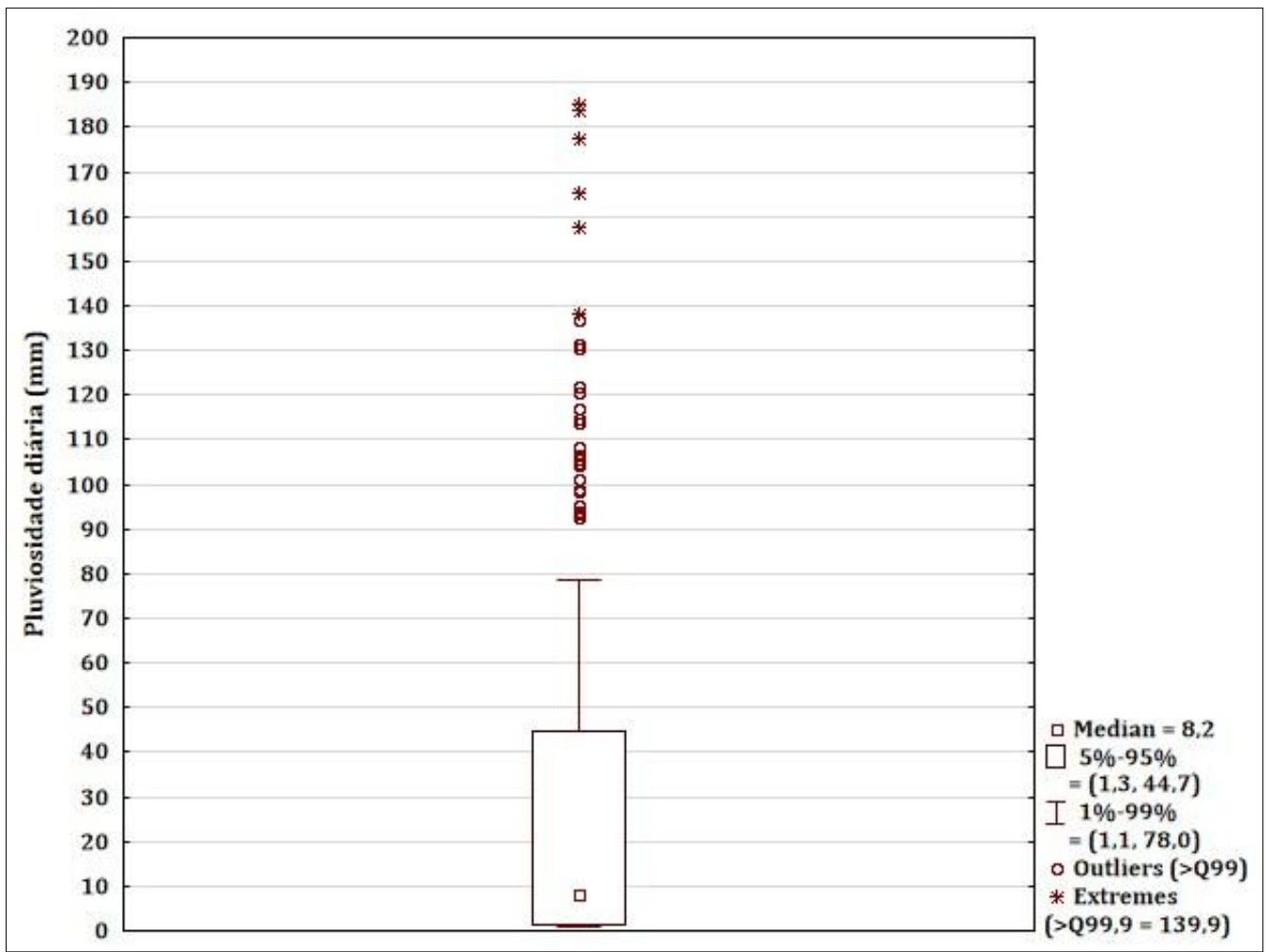

Figura 7 - Boxplot da pluviosidade diária $(\mathrm{mm})$ do posto pluviométrico anômalo (PPA) da bacia hidrográfica do rio Alto Iguaçu - PR. 

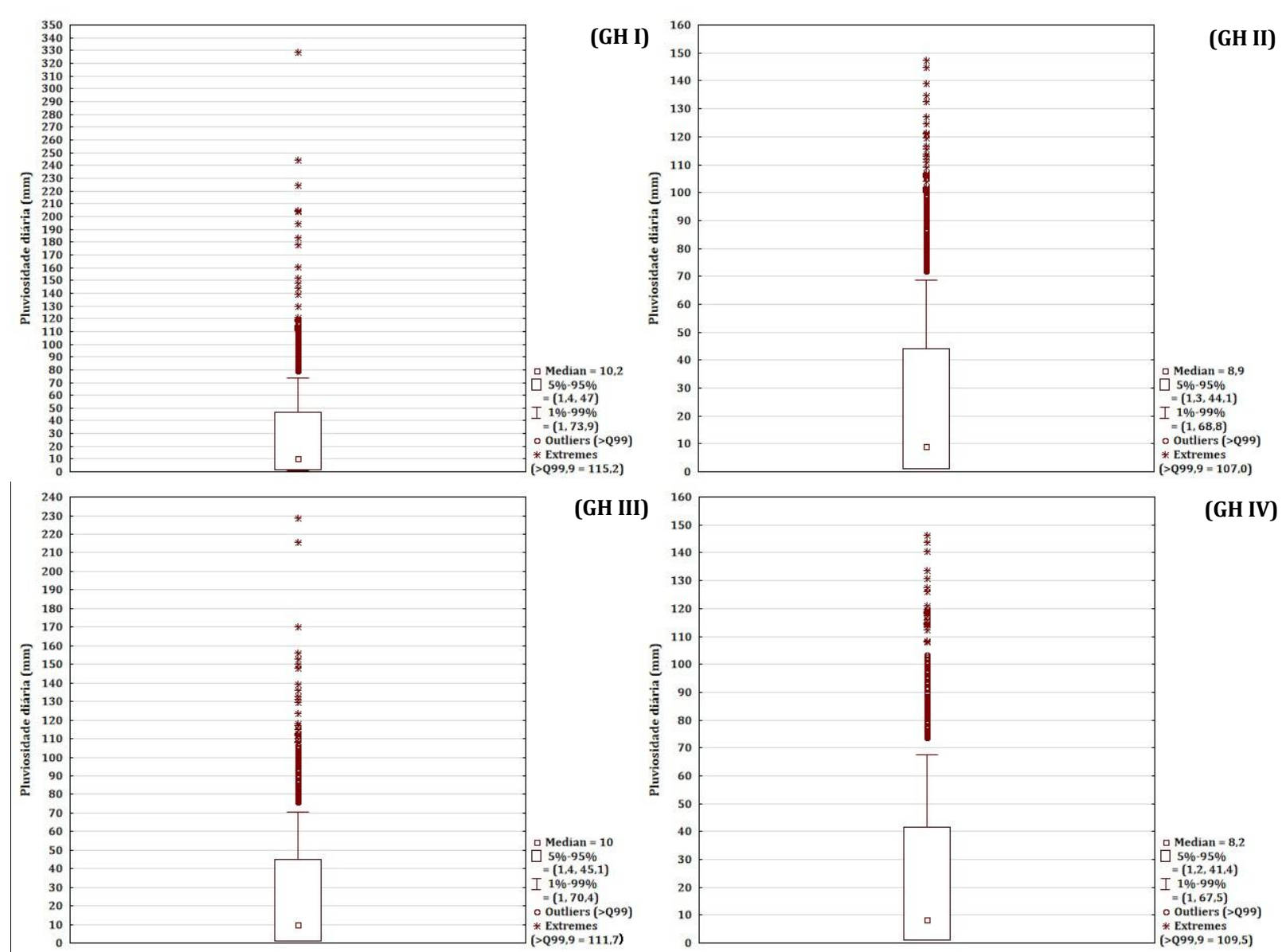

Figura 8 - Boxplots da pluviosidade diária $(\mathrm{mm})$ nos grupos homogêneos da bacia hidrográfica do rio Alto Iguaçu - PR. 

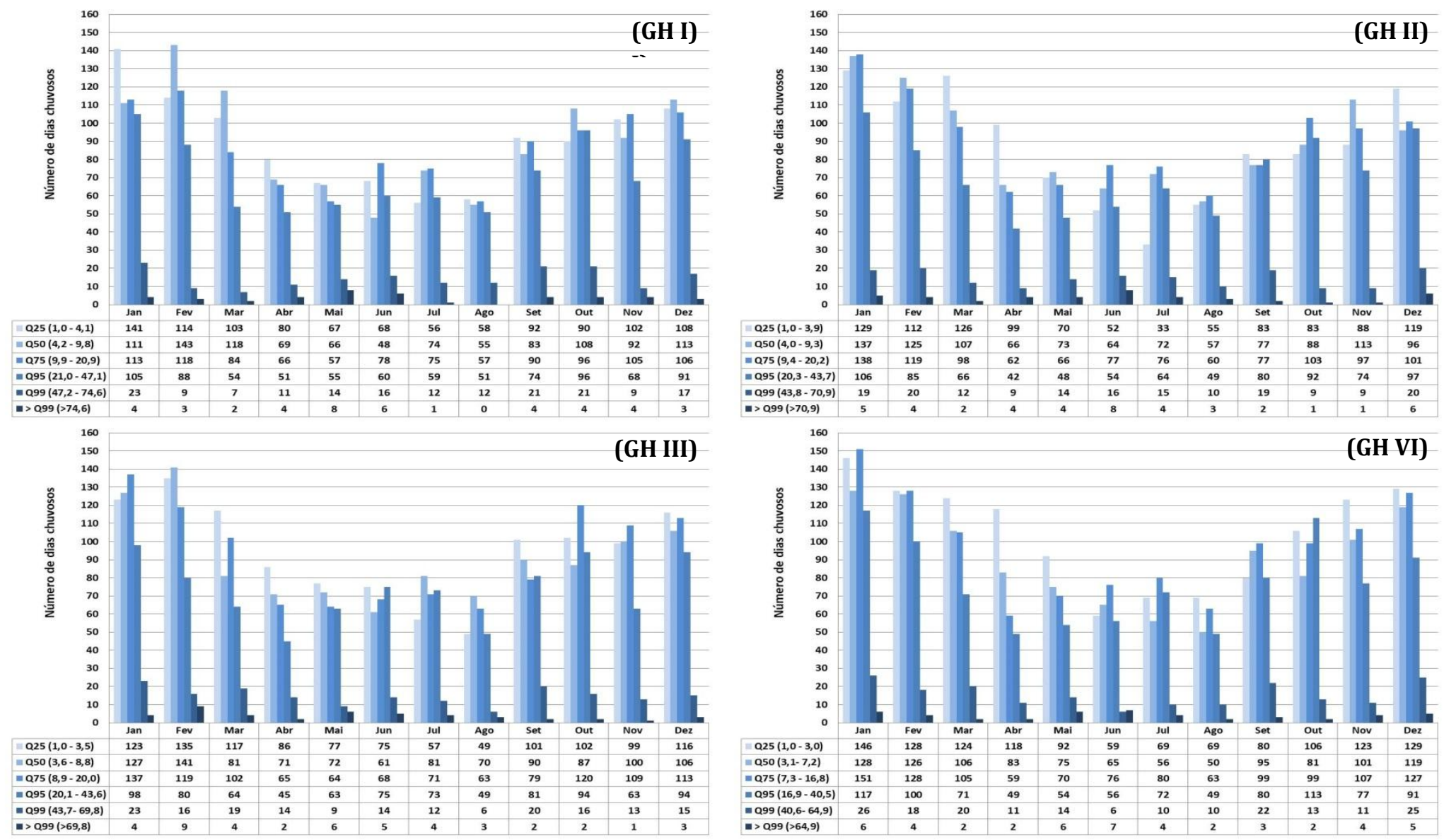

Figura 9 - Classes dos quantis e o número de dias chuvosos em São Mateus do Sul (GH I), Quitandinha (GH II), Lapa (GH III) e Pinhais (GH VI) na bacia hidrográfica do Alto Iguaçu - PR. 


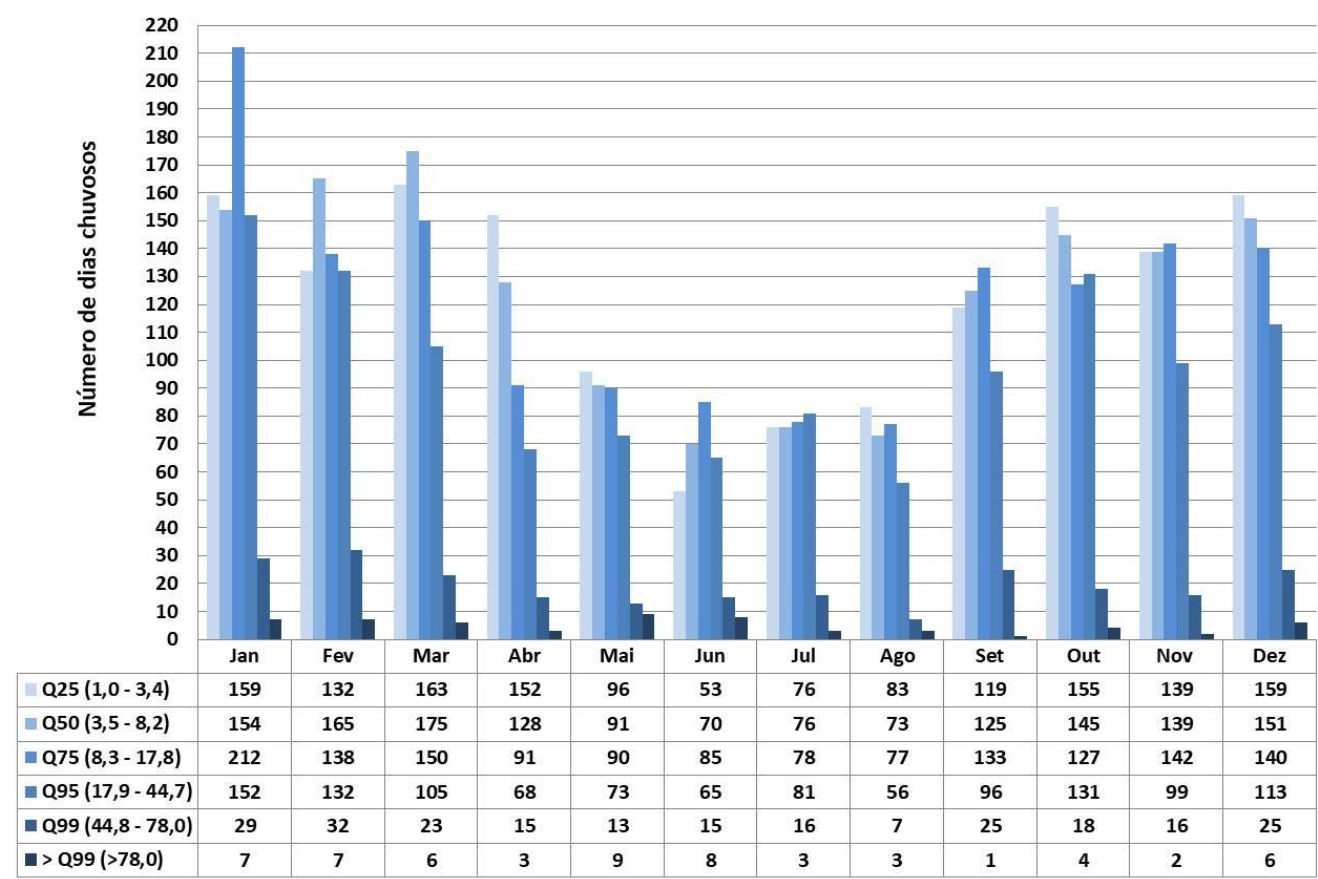

Figura 10 - Classes dos quantis e o número de dias chuvosos em Piraquara (Mananciais da Serra - PPA) na bacia hidrográfica do rio Alto Iguaçu - PR.

Terassi et al. (2018) destacaram que a diminuição da frequência e da intensidade das precipitações no período invernal se deve a restrição dos FP na geração das precipitações, ao passo que durante o verão a alternância de sistemas atmosféricos intertropicais e a FP contribui para os totais mais elevados de precipitações, conclusões dadas a partir dos resultados obtidos por estes autores e à dinâmica atmosférica regional, conforme as observações de Silva et al. (2006), Reboita et al. (2010) e Reboita et al. (2012).

Portanto, observa-se que o padrão de distribuição mensal da frequência e intensidade das precipitações diárias obtidas para a BHAI é próximo ao observada para a RPN e, no entanto, por situar-se em mais próxima ao domínio climático subtropical, conforme indicam Nimer (1989), Reboita et al. (2012) e Dubreuil et al. (2017), as precipitações mais intensas ocorrem com maior frequência do que no domínio climático mais próximo tropical do Brasil central, como é o caso do norte paranaense. Isto se deve pela atuação mais constante da FP na geração das precipitações no setor mais meridional do estado do Paraná, conforme observaram Borsato e Mendonça (2015). Ainda, Leite et al. (2001) observaram que os maiores percentuais da frequência de precipitações superiores a $50 \mathrm{~mm}$ em Ponta Grossa (PR), localidade próxima área em estudo, são mais elevados entre maio e julho, o que é um indicativo de maiores totais pluviais gerados pela FP para a BHAI.

\section{CONSIDERAÇÕES FINAIS}

A análise multivariada com base na análise de agrupamento possibilita avaliar de forma setorizada a distribuição espaço-temporal das precipitações e 
da erosividade para a BHAI. O posto pluviométrico anômalo é isoladamente o que tem os maiores totais anuais de precipitação e erosividade. Os setores oeste e noroeste, compostos pelos grupos GH I e GH II têm os maiores totais anuais de pluviosidade e, no entanto, o GH III é maior erosividade em comparação ao GH II, uma vez que este índice esteja diretamente associado à distribuição mensal da pluviosidade e este GH apresenta o aumento significativo da erosividade na estação do verão.

No estudo a concentração de $70 \%$ é observada nos totais anuais da erosividade entre setembro e março, embora os GH I e GH III apresentem maiores valores no período de inverno em comparação as demais estações do ano. A baixa variabilidade interanual da pluviosidade e da erosividade é identificada no estudo. Embora o aumento/diminuição das precipitações e do potencial erosivo estivesse relacionado aos períodos de maior/menor intensidade das fases dos ENOS, não necessariamente a variabilidade interanual resume-se a anomalia de temperatura de superfície do Oceano Pacífico.

O PPA de Piraquara (Mananciais da Serra), devido à condição orográfica, caracteriza-se pela maior frequência e intensidade das precipitações diárias. Dentre os grupos homogêneos, os grupos GH I e GH III mostraram os maiores valores das classes de quantis, isso possibilita associar a intensidade das precipitações diárias ao potencial erosivo, sendo que estes atributos são indícios da concentração pluvial e, consequentemente, de maiores impactos e repercussões socioambientais. Igualmente, os repiques de erosividade em maio e outubro estão diretamente associados ao aumento das precipitações diárias nos grupos GH I e GH III. O período entre setembro e março mostraram com maior frequência os registros das precipitações mais intensas e, entretanto, devido à predominância do clima subtropical, alguns setores mostraram maior da ocorrência dos registros das precipitações entre R95p e R99p, sobretudo nos meses de maio e junho.

\section{AGRADECIMENTOS}

O presente trabalho foi realizado com apoio do Programa Nacional de Cooperação Acadêmica da Coordenação de Aperfeiçoamento de Pessoal de Nível Superior - Edital CAPES 071/2013 - Processo número 88881.068465/2014-01. Os autores agradecem a Coordenação de Aperfeiçoamento de Pessoal de Nível Superior pela concessão das bolsas de Doutorado e Mestrado ao primeiro e segundo autores, nesta ordem. Agradecimentos ao Conselho Nacional de Desenvolvimento Científico e Tecnológico pela Bolsa de Produtividade em Pesquisa - Nível 1D e 2 concedidas ao terceiro autor (303676/2013-2) e quarto autor (306410/2015-0).

\section{REFERÊNCIAS}

ALMEIDA; C.O.S.; AMORIM, R.S.S.; ELTZ, F.L.F.; COUTO, E.G.; JORDANI, S.A. Erosividade da chuva em municípios do Mato Grosso: Distribuição sazonal e correlações com dados pluviométricos. Revista Brasileira de Engenharia Agrícola e Ambiental, Campina Grande, v.16, n.2, p.142-152, 2012. 
ÁlVARES, C.A.; STAPE, J.L.; SENTELHAS, P.C.; DE MORAES GONÇALVES, J.L.; SPAROVEK, G. Köppen's climate classification map for Brazil. Meteorologische Zeitschrift, Berlin, v.22, n.6, p.711-728, 2013.

AMORIM, M.C.C.T.; MONTEIRO, A. Episódios extremos de precipitação e fragilidade dos ambientes urbanos: exemplos de Portugal e do Brasil. Territorium, Coimbra, v.17, n.1, p.5-15, 2010.

ANANIAS, D.S.; SOUZA, E.B.; SOUZA, P.F.S. SOUZA, A.M.L.; VITORINO, M.I.; TEIXEIRA, G.M.; FERREIRA, D.B. Climatologia da estrutura vertical da atmosfera em novembro para Belém - PA. Revista Brasileira de Meteorologia, São Paulo, v. 25, n.2, p.218-226, 2010.

APARECIDO, L.E.O; ROLIM, G.S.; RICHETTI, J.; SOUZA, P.S.; JOHANN, J.A. Köppen, Thornthwaite and Camargo climate classifications for climatic zoning in the State of Paraná, Brazil. Ciência e Agrotecnologia (Online), Lavras, v. 40, n. 4, p. 405-417, 2016.

ARMOND, N.B.; SANT'ANNA NETO, J.L. Entre eventos e episódios: ritmo climático e excepcionalidades para uma abordagem geográfica do clima no município do Rio de Janeiro. Revista Brasileira de Climatologia, Curitiba, v.20, n.13, p.5-28, 2017.

ARMOND, N.B.; SANT'ANNA NETO, J.O. The Urban Climate System and the Impacts of Flooding on Rio de Janeiro, Brazil. In: HENRÍQUEZ, C.; ROMERO, H. (Org.). Urban Climates in Latin America. 1aEdição. Switzerland: Springer International Publishing, v.1, p.259-2801, 2019.

BACK, A.J.; POLETO, C. Distribuição espacial e temporal da erosividade das chuvas no estado de Santa Catarina, Brasil. Revista Brasileira de Climatologia, v. 22 , n.1, p.381-403, 2018.

BALDO, M.C.; NERY, J.T.; MARTINS, M.O.F. Análise da estrutura da precipitação pluviométrica na região Sul do Brasil. Boletim de Geografia (UEM), Maringá, v. 19, n.1, p.115-128, 2001.

BORSATO, V.A.; MENDONÇA, F.A. Participação da massa polar atlântica na dinâmica dos sistemas atmosféricos no Centro Sul do Brasil. Mercator, Fortaleza, v.14, n.1, p.113-130, 2015.

BRITO, T.T.; OLIVEIRA-JÚNIOR, J.F.; LYRA, G.B.; GOIS, G.; ZERI, M. Multivariate analysis applied to monthly rainfall over Rio de Janeiro state, Brazil. Meteorology and Atmospheric Physics, Berlin, v.129, n.5, p.469-478, 2016.

CÂNDIDO, D.H.; NUNES, L.H. Influência da orografia na precipitação da área entre o vale do rio Tietê e a Serra da Mantiqueira. Geousp, São Paulo, v.1, n.24, 2008.

CARDOZO, A.B.; REBOITA, M.S.; GARCIA, S.R. Climatologia de Frentes Frias na América do Sul e sua relação com o Modo Anular Sul. Revista Brasileira de Climatologia, Curitiba, v.17, n.1, p.9-29, 2015.

DUBREUIL, V.; FANTE, K.P.; PLACHON, O.; SANT'ANNA NETO, J.L. Les types de climats annuels au Brésil: une application de la classification de Köppen de 1961 à 2015. EchoGéo, Paris, v.3, n 41, p.1-27, 2017. 
EASTERLING, D.R.; MEEHL, G.A.; PARMESAN, C.; CHANGNON, S.A.; KARL, T.R.; MEARNS, L.O. Climate extremes: Observations, modeling, and impacts. Science, v.289, n.5487, p.2068-2074, 2000.

FREITAS, J.C.; ANDRADE, A.R.S.; BRAGA, C.C.; GODOI NETO, A.H.; ALMEIDA, T.F. Análise de agrupamento na identificação de regiões homogêneas de índices climáticos no Estado da Paraíba, Brasil. Revista Brasileira de Geografia Física, Recife, v.6, n.4, p.732-748, 2013.

FRITZSONS, E.; MANTOVANI, L.E.; WREGE, M.S.; CHAVES NETO, A. Análise da pluviometria para definição de zonas homogêneas no estado do Paraná. RA'E GA: o Espaço Geográfico em Análise, Curitiba, v.23, n.1, p.555-572, 2011.

GOUVEA, R.L.; CAMPOS, C.C.; MENEZES, J.T.; MOREIRA, G.F. Análise da frequência de precipitação e caracterização de anos secos e chuvosos para a bacia do Alto Itajaí. Revista Brasileira de Climatologia, v.22, n.14, p.309-322, 2018.

GRIMM, A.M. Clima na Região Sul. In: CAVALCANTI, I.F.A.; FERREIRA, N.J.; SILVA, M.G.A.J.; SILVA DIAS, M.A.F (Org.). Tempo e Clima no Brasil. $1^{a}$ Edição. São Paulo, Oficina de Textos, p.259-275, 2009.

HOYOS, N.; WAYLEN P.; JARAMILLO A. Seasonal and spatial patterns of erosivity in a tropical watershed of the Colombian. Journal of Hidrology, Amsterdam, v. 314, n.1-4, p. 77-191, 2005.

IBGE (Instituto Brasileiro de Geografia e Estatística). Conheça cidades e estados do Brasil. 2018. Disponível em: <https://cidades.ibge.gov.br/>. Acesso em 27 de fevereiro de 2019.

INMET (Instituto Nacional de Meteorologia). Normais climatológicas do Brasil. 2018. Disponível em: <http://www.inmet.gov.br/portal/index.php?r=clima/nor

maisclimatologicas>. Acesso em 06 de março 2018.

IPARDES (Instituto Paranaense de Desenvolvimento Econômico e Social). Perfil avançado dos municípios. 2016. Disponível em: <http://www.ipardes.gov.br/ind ex.php?pg_conteudo=1\&cod_conteudo=29>. Acesso em 25 de novembro de 2016.

ITCG (Instituto de Terras, Cartografia e Geodésia). Produtos Cartográficos. Disponível em: <http://www.itcg.pr.gov.br/modules/conteudo/conteudo. php?c

onteudo=47. Acesso em 14 de janeiro de 2017.

KELLER FILHO, T; ASSAD, E.D.; LIMA, P.R.S.R. Regiões pluviometricamente homogêneas no Brasil. Revista Brasileira de Pesquisa Agropecuária, Brasília, v. 40, n.4, p.311-322, 2005.

KÖPPEN, W. Climatologia: com un estúdio de los climas de la tierra. México. Ed. Fondo de Cultura Econômica, 1948.

LEITE, M.L.; ADACHESKI, P. A.; VIRGENS FILHO, J.S. Análise da frequência e da intensidade das chuvas em Ponta Grossa, estado do Paraná, no período entre 1954 e 2001. Acta Scientiarum. Technology, Maringá, v.33, n.1, p.57-64, 2001. 
MA, X.; YANDONG, H.; XU, J.; VAN NOORDWIJK,M; LU,X. Spatial and temporal variation in rainfall erosivity in a Himalayan watershed. Catena, Amsterdam, v. 121, n.1, p.248-259, 2012.

MAACK, R. Geografia Física do Estado do Paraná. 4a Edição. Ponta Grossa: Editora UEPG. 2012. 526p.

MELLO, Y.R.; LOPES, F.C.A.; ROSEGHINI, W.F.F. Características climáticas e análise rítmica aplicada a episódios extremos de precipitação e temperatura no município de Paranaguá, PR. Revista Brasileira de Climatologia, Curitiba, v.20, n.1, p.313-336, 2017.

MINEROPAR. Atlas Geológico do estado do Paraná. 2001. Minerais do Paraná, Curitiba. 2001. 125p. CD ROM.

NASCIMENTO, F.C.A.; ARAÚJO, F.R.C.D.; BRAGA, C.C.; COSTA, E.V.S. Análise dos padrões espaciais e temporais da precipitação no Estado do Maranhão. Revista Brasileira de Geografia Física, Recife, v. 8, n. 2, p. 422-430, 2015.

NERY, J.T.; STIVARI, S.M.S.; MARTINS, M.L.O.F.; SILVA, E.S.; SOUSA, P. Estudo da precipitação do estado do Paraná e sua associação à temperatura da superfície do Oceano Pacífico. Revista Brasileira de Agrometeorologia, Santa Maria, v.13, n.1, p.161-171, 2005.

NERY, J.T.; CARFAN, A.C. Re-analysis of pluvial precipitation in southern Brazil. Atmosféra, Cidade do México, v.27, n.2, p.103-114, 2014.

NETTO, C.F.; VIRGENS FILHO, J.S.; NEVES, G.L. Análise da erosividade da chuva no estado do Paraná e cenários futuros impactados por mudanças climáticas globais. Revista Brasileira de Climatologia, v.22, n.14, p.404-422, 2018.

NIMER. E. Climatologia do Brasil. 2a Edição. Rio de Janeiro: Instituto Brasileiro de Geografia e Estatística, 1989. 421p.

OSCAR JÚNIOR, A.C. Extremos atmosféricos e desastres hidrometeorológicos em Duque de Caxias (RJ). Revista Brasileira de Climatologia, Curitiba, v.17, n.11, p.189-205, 2015.

OLIVEIRA, P.T.S.; WENDLAND, E.; NEARING, M.A. Rainfall erosivity in Brazil: a review. Catena, Amsterdam, v.100, n.1, p.139-147, 2012.

PANAGOS, P.; BORELLI, P.; MEUSBURGER, K.; YU, B.; KLIK, A.; JAE LIM, K.; YANG, J.E.; NI, J.; MIAO, C.; CHATTOPADHYAY, N.; SADEGHI, S.H.; HAZBAVI, Z.; ZABIHI, M.; LARIONOV, G.A.; KRASNOV, S.F.; GOROBETS, A.V.; LEVI, Y.; ERPUL, G.; BIRKEL, C.; HOYOS, N.; NAIPAL, V.; OLIVEIRA, P.T.S.; BONILLA, C.A.; MEDDI, M.; NEL, W.; AL DASHTI, H.; BONI, M.; DIODATO, N.; VAN OOST, K.; NEARING, M.; BALLABIO, C. Global rainfall erosivity assessment based on high-temporal resolution rainfall records. Nature, Londres, v.7, n.4175, p.1-12, 2017.

PRADO, J.P.B.; NÓBREGA, M.T. Determinação de perdas de solo na bacia hidrográfica do córrego Ipiranga em Cidade Gaúcha, Estado do Paraná, com aplicação da Equação Universal de Perdas de Solo (EUPS). Acta Scientiarum Technology, Maringá, v.27, n.1, p.33-42, 2005.

QUADRO, M. F. L.; SILVA DIAS, M. A. F.; HERDIES, D. L.; GONCALVES, L. G. G. Análise climatológica da precipitação e do transporte de umidade na região da 
ZCAS através da nova geração de reanálises. Revista Brasileira de Meteorologia, São Paulo, v.27, n.2, p.287-294, 2012.

REBOITA, M.S.; GAN, M.A.; ROCHA, R.P.; AMBRIZZI, T. Regimes de precipitação na América do Sul. Revista Brasileira de Meteorologia, São Paulo, v.25, n.2, p. 185-204, 2010.

REBOITA, M.S.; KRUSCHE, N.; AMBRIZZI, T.; ROCHA, R.P. Entendo o Tempo e o Clima na América do Sul. Terrae Didatica, v.8, n.1, p.34-50, 2012.

RITTER, L.M.O; ALMEIDA, C.G.; MORO, R.S. Caracterização fitofisionômica dos fragmentos campestres com fáceis de cerrado em Ponta Grossa, Paraná. Revista Brasileira de Biociências, Porto Alegre, v.5, n.2, p.192-194, 2007.

RODERJAN, C.V.; GALVÃO, F.; KUNIYOSHI, Y.S.; HATSCHBACH, G.G. As unidades fitogeográficas do estado do Paraná. Ciência \& Ambiente, Santa Maria, v.24, n.1, p.75-92, 2002.

RUFINO, R.L.; BISCAIA, R.C.M.; MERTEN, G.H. Determinação do potencial erosivo da chuva do estado do Paraná, através de pluviometria: terceira aproximação. Revista Brasileira de Ciência do Solo, Campinas, v.17, n.1, p.439444, 1993.

SANTOS, A.P.P.; ARAGÃO, M.R.S.; CORREIA, M.F.; SANTOS, S.R.Q.; SILVA, F. D.S.; ARAÚJO, H. A. Precipitação na cidade de Salvador: variabilidade temporal e classificação em Quantis. Revista Brasileira de Meteorologia, São Paulo, v.31, n.4, p. 1-14, 2016.

SCHICK, J.; BERTOL, I.; COGO, N.P.; GONZÁLEZ, A.P. Erosividade das chuvas em Lages, Santa Catarina. Revista Brasileira de Ciência do Solo, Viçosa, v.38, n. 6, p.1890-1905, 2014.

SELUCHI, M.E.; CHOU, S.C. Synoptic patterns associated with landslides events in the Serra do Mar, Brazil. Theoretical and Applied Climatology, Berlim, v.98, n. 1, p.67-77, 2009.

SEPÚLVEDA, S.A.; PETLEY, D.N. Regional trends and controlling factors of fatal landslides in Latin America and the Caribbean. Natural Hazards and Earth System Sciences, v.15, n.1, p.1821-1833, 2015.

SILVA, A.M. Rainfall erosivity map for Brazil. Catena, Amsterdam, v.57, n.3, p. 251-259. 2004.

SILVA, C. B.; SANT'ANNA NETO, J. L.; TOMMASELLI, J. T. G.; PASSOS, M. M. Dinâmica atmosférica e análise geoestatística do clima na área de integração paisagística 'Raia Divisória' SP/PR/MS: uma proposta de tipologia climática. Revista Brasileira de Climatologia, Curitiba, v.2, n.1, p.53-70, 2006.

SILVA, A.M.; WIECHETECK, M.; ZUERCHER, B.W. Spatial assessment of indices for characterizing the erosive force of rainfall in El Salvador Republic. Environmental Engineering Science, v.28, n.4, p.309-316, 2011.

SOUZA, V.; GASPARETTO, N. V. L. Aplicação da equação universal de perdas de solo (EUPS) na bacia do córrego Pinhalzinho Segundo, noroeste do Paraná. Revista Brasileira de Geomorfologia, Uberlândia, v.13, n.3, p.267-278, 2012. 
SOUZA, W.M.; AZEVEDO, P.V.; ARAÚJO, L.E. Classificação da precipitação diária e impactos decorrentes dos desastres associados às chuvas na cidade do Recife - PE. Revista Brasileira de Geografia Física, Recife, v.5, n.2, p.250-268, 2012.

TEDESCHI, R.G.; GRIMM, A.M.; CAVALCANTI, I.F. Influence of Central and East ENSO on extreme events of precipitation in South America during austral spring and summer. International Journal of Climatology, v.35, n.8, p.2045-2064, 2015.

TERASSI, P.M.B.; SILVEIRA, H.; GRAÇA, C.H. Intensidade pluviométrica diária e a erosividade na Unidade Hidrográfica Pirapó, Paranapanema III e IV, estado do Paraná. Caminhos de Geografia, Uberlândia, v.17, n.59, p.84-102, 2016.

TERASSI, P.M.B.; SILVEIRA, H.; OLIVEIRA-JÚNIOR, J.F. Variabilidade pluviométrica e a erosividade das chuvas na Unidade Hidrográfica Pirapó, Paranapanema III e IV - Paraná. RA'E GA: Espaço Geográfico em Análise, Curitiba, v.39, n.1, p.76-91, 2017.

TERASSI, P.M.B.; GALVANI, E. Identification of homogeneous rainfall regions in the eastern watersheds of the State of Paraná, Brazil. Climate, v.5, n.3, p.5365, 2017a.

TERASSI, P.M.B.; GALVANI, E. O efeito orográfico da Serra do Mar e o potencial erosivo das chuvas nas bacias hidrográficas do Ribeira e Litorânea - Paraná. Revista Brasileira de Climatologia, v.21, n.13, p.327-345, 2017b.

TERASSI, P.M.B.; OLIVEIRA-JÚNIOR, J.F.; GALVANI, E.; GOIS, G. Frequência e intensidade pluviométrica na região Norte do estado do Paraná, Brasil. Revista do Departamento de Geografia (USP), v.35, n.1, p.122-135, 2018.

TOMAZONI, J. C.; GUIMARÃES, E. A sistematização dos fatores da EUPS em SIG para quantificação da erosão laminar na bacia do rio Jirau. Revista Brasileira de Cartografia, Rio de Janeiro, v.57, n.3, p. 235-244, 2005.

TOMMASELLI, J.T.G.; FREIRE, O.; CARVALHO, O. Erosividade da chuva na região oeste do estado de São Paulo. Revista Brasileira de Agrometeorologia, Santa Maria, v.7, n.2, p.269-276, 1999.

TRINDADE, A.L.F.; OLIVEIRA, P.T.S.; ANACHE, J.A.A.; WENDLAND, E. Variabilidade espacial da erosividade das chuvas no Brasil. Revista de Pesquisa Agropecuária, Brasília, v.51, n.12, p.1918-1928, 2016.

WALTRICK, P.C.; MACHADO, M.A.M.; OLIVEIRA, D.; GRIMM, A.M.; DIECKOW, J. Erosividade de chuvas no estado do Paraná: Atualização e influência dos eventos "El Niño" e "La Niña". Boletim Técnico da Sociedade Brasileira de Ciência do Solo. Curitiba, 2011. 36p.

WALTRICK, P.C.; MACHADO, M.A.M.; DIECKOW, J.; OLIVEIRA, D. Estimativas da erosividade de chuvas no estado do Paraná pelo método da pluviometria: Atualização com dados de 1986 a 2008. Revista Brasileira de Ciência do Solo, Viçosa, v.39, n.1, p.256-267, 2015.

WANDERLEY, L.S.A.; NÓBREGA, R.S.; ANJOS, R.S.; ALMEIDA, C.A.P. As chuvas na cidade do Recife: uma Climatologia de extremos. Revista Brasileira de Climatologia, Curitiba, v.22, n.14, p.149-164, 2018.

WREGE, M.S.; FRITZSONS, E.; CARAMORI, P.H.; RICCE, W.S.; RADIN, B.; STEINMETZ, S.; REISSER JÚNIOR, C. Regiões com similaridade de 
comportamento hídrico no Sul do Brasil. RA'E GA: o Espaço Geográfico em Análise, Curitiba, v.38, n.1, p.363-382, 2016.

WU C.; HUANG, G. Changes in heavy precipitation and floods in the upstream of the Beijiang River basin, South China. International Journal of Climatology, Oxford, v.35, n.10, p.2978-2992, 2015.

ZANDONADI, L.; ACQUAOTTA, F.; FRATIANNI, S.; ZAVATTINI, J. A. Changes in precipitation extremes in Brazil (Paraná River Basin). Theoretical and Applied Climatology, Berlim, v.119, n.1, p.1-18, 2015.

ZANELLA, M.E. Eventos pluviométricos intensos e impactos gerados na cidade de Curitiba/PR- Bairro Cajuru: um destaque para as inundações urbanas. Mercator, Fortaleza, v.5, n.9, p.61-74, 2006.

ZANELLA, M.E. Impactos pluviais no Bairro Cajuru - Curitiba - PR. Mercator, Fortaleza, v.6, n.11, p.93-105, 2007.

ZANELLA, M. E.; SALES, M. C. L.; ABREU. N.J. Análise das precipitações diárias intensas e impactos gerados em Fortaleza - CE. Geousp, São Paulo, v.25, n.1, p.53-68, 2009.. 